\title{
R\&D and Innovations on Tertiary Sector's Performance and Its Contribution to the World Economic Growth
}

\author{
Yasuyuki Nishigaki ${ }^{1}$, Leisa Cristina Sena Moreno ${ }^{2}$ \\ ${ }^{1}$ Faculty of Economics, Ryukoku University, Kyoto, Japan \\ ${ }^{2}$ Graduate School of Economics, Ryukoku University, Kyoto, Japan \\ Email address: \\ nisigaki@econ.ryukoku.ac.jp (Y. Nishigaki), e14d501@mail.ryukoku.ac.jp (L. C. S. Moreno)
}

\section{To cite this article:}

Yasuyuki Nishigaki, Leisa Cristina Sena Moreno. R\&D and Innovations on Tertiary Sector's Performance and Its Contribution to the World Economic Growth. International Journal of Economic Behavior and Organization. Special Issue: Recent Developments of Economic Theory and Its Applications. Vol. 3, No. 2-1, 2015, pp. 31-38. doi: 10.11648/j.ijebo.s.2015030201.16

\begin{abstract}
Growth effects of R\&D, especially in the service sector, are focused in this paper. By using a Romer type growth model with a R\&D sector and a final goods retailing sector, we point out growth effects from the labor share of the R\&D sector and the service sector. From the empirical analysis on the steady state equation, a positive per-capita income contribution from service sector' GDP share is put out at light as well as the number of researcher is here indicated for its weight on understanding the subject. And for world growth data we apply principal component analysis: a strong causality effect among per-capita GDP, R\&D investment, and service sector share is deduced.
\end{abstract}

Keywords: Endogenous Economic Growth, R\&D, Service Sector Growth, World Development

\section{Introduction and Literature Review}

"Economic growth is a complex process, which depends on many variables including human and physical capital, trade, technological change, political conditions and quality of institutions" (Sahli and Carey 2011).

Romer (1990) highlighted technological progress as one of the engines of economic growth and indicated theoretically why the advanced economies have grown at something like 2 percent per year for the last century. In empirical studies of economic growth, Solow (1957) performed a simple accounting estimation to break down growth in GDP into growth in labor and growth in technological change and indicated that considerable part of the GDP growth was explained by technological change. Concerning $R \& D$ investment, Gordon (1990) had estimated that many of the gains of improved capital goods by technological progress reflected in GDP growth in addition to the product innovations or generating new and improved goods.

Barro and Sala-i-Martine (2004) presented empirical study investigated the stylized facts of economic growth. They indicated a persistent growth in the per-capita output and in the labor productivity as well as the considerable differences in the growth rate of the labor productivity in different economies. Although they did not make direct address on growth effects of technology progress, in their investigation of a growth accounting, they suggested R\&D spending as a determinant of the total factor productivity growth in some rapid developing countries such as Hong Kong, Singapore, South Korea and Taiwan.

Djellal et al (2003), on the other hand, focused R\&D and its importance on growth and development of service sector. They clarify the role of the R\&D in services on growth and so on the development of economy by amending its definition. In this paper, we will address our attentions to the importance of $\mathrm{R} \& \mathrm{D}$ in the service sector according to the views of Djellal et al, and we will investigate its impact on the growth of world economy.

In the theoretical part of the paper, we will show the importance of the innovation and technological progress in the service sector to economic growth by using the three sector economic growth model which include R\&D and service sector in addition to the production sector according to Romer (1990). After deducing hypothesis from the theoretical investigation, we will test the validity of the theoretical consequences empirically by using economic development indicators of the World Bank. The aim being to 
enlighten the R\&D and Innovation as the real value of the Tertiary Sector's contributions to World Economic Growth.

\section{The Importance of $R \& D$ and Innovation in the Service Sector's Performance and Its Impact on the Growth of World Economy}

Research and development (R\&D) is underestimated in services (Djellal et al 2003). According to Djellal et al 2003, services are constantly challenging economic theory and the existing evaluation systems. It's perfectly clear that productivity in services is no lower than in other sectors of the economy, and there is no less innovation. As their article says it is our theoretical concepts and the measurement systems arising out of them that are unsuitable. So similarly, it is likely that R\&D and innovations in tertiary sector's performance is underestimated when coming up to its contribution to the world economic growth.

In the same time during the past few decades, throughout the world, we have witnessed an increasingly strong development of the tertiary sector which has led to the significant growth of the services percentage in the formation of the GDP exceeding easily $70 \%$.

However and despite the R\&D's strategic importance it seems hard to evaluate it in service firms and in service industry. The sector that now a days dominates the charts and tables showing out the growth all over the world.

Djellal et al (2003) focused R\&D and its importance on growth and development of service sector. They clarify the role of the $R \& D$ in services on growth and so on the development of economy by amending its definition. Their main concern relies on their willing to explain the inability of the definitions and indicators of R\&D to take account of certain specificities of the "systematic creation of new knowledge" in services. R\&D was 1 a good indicator of innovativeness at both micro and macro levels. In the traditional sense, according to the Frascati Manual (OECD, 1993, paragraph 57), "Research and experimental development $(\mathrm{R} \& \mathrm{D})$ comprise creative work undertaken on a systematic basis in order to increase the stock of knowledge, including knowledge of man, culture and society, and the use of this stock of knowledge to devise new applications."

R\&D is a term that recovers three activities: basic research (experimental or theoretical work to acquire new knowledge), applied research (also to acquire new knowledge but directed towards specific practical aim) and experimental development (acquired knowledge directed towards improve, install or producing new materials, products and services). Three fundamental principles underlie these definitions: the notion of the production of knowledge; the systematic nature of this production and the criterion of an appreciable element of novelty in the knowledge.

These lines mean that R\&D is an intentional and organized

1 Djellal et al. 2003. activity. To distinguish R\&D from related scientific, technological and industrial activities (OECD, 1993) it is needed to know: the nature of the project objectives; the type of personnel allocated to the project; the method used; the nature and source of the funding; the degree of generality of the conclusions or results obtained, etc. According to service characteristics and specificities various spheres 2 of $\mathrm{R} \& \mathrm{D}$ depends on the type of service activity (implications of the relationship to technologies, product and process innovation as well as back-office and front-office technologies - ref. Frascati Manual).

Djellal et al (2003) think it is better to question why a single definition for goods and services and in the same concern what amendments should be proposed.

These authors then suggest RD\&I (research, development and innovation) and RD\&D (research, design and experimental development) where both suggestion follow their willing to "make explicit certain elements that have hitherto been implicit: this is one of the basic preconditions for breaking out of industrialist inertia, and these minor modifications may lead to major changes in the identification and measurement of R\&D in services" and so in the evaluation of Innovation through tertiary sector's performance.

An important consequence of the new definition of R\&D is "an attempt to re-establish some degree of consistency between the definition of research and researcher". Researchers that in our empirical evaluation are taken in account as part of the labor indicator. They "are professionals in the natural sciences or the social sciences and humanities (including various categories of designers and 'developers') engaged in the conception or creation of new knowledge, products, processes, services, methods, and systems, and in the management of the projects concerned".

Many types of creative activities, including design and development or service engineering, which inextricably combine products, process and organization have done a lot to elude attempts at their own measurement. And services are constantly challenging economic theory and evaluation systems once its sector performance has lately been all over the statistical reports of growth.

Shall this article come to as an additional contribution on revealing the causality effect among per-capita GDP and R\&D in/and service sector.

\section{Theoretical Model of R\&D in Service Sector and Economic Growth}

Romer (1990) addressed endogenous technological progress by introducing the sector for researching new idea and technology. Due to the non-rivalrous property of new knowledge, a fixed cost of production and zero marginal cost incurs to R\&D process which is closely tied to the presence of increasing returns to scale and imperfect competition

2 OECD 1993 
(Jones (1997): that is technology progress occurs as profit maximizing firms or inventors. The model includes, therefore, a monopolistic intermediate goods production sector which produces intermediate goods (or capital goods) that are sold to the final goods retailing sector (service sector). According to a model introduced by Jones (1997), we will investigate implications of $R \& D$ and service sector growth in a three sector endogenous economic growth model.

\subsection{Service Sector}

The service sector of the Romer model consists of a large number of competitive firms that combine labor and intermediate goods to produce the final good Y. The production function is specified in a slightly different way to the ordinary growth model to reflect the fact that there are many inter-mediate goods in the model:

$$
Y=L_{Y}^{1-\alpha} \sum_{j=1}^{A} X_{j}^{\alpha}
$$

Output $\mathrm{Y}$ is produced using labor $L_{Y}$ and a number of different inter-mediate goods, $X_{j}$, which we also can call "capital goods." $A$ measures the number of inter-mediate goods that are available to be used in the final goods sector and the firms in the service sector take this number as given. Inventions or ideas in the model correspond to the creation of new intermediate goods that can be used by the service sector to produce its output.

For the analytical reason of model tractability, we replace the summation in the production function with an integral:

$$
Y=L_{Y}^{1-\alpha} \int_{0}^{A} X_{j}^{\alpha} d j .
$$

Then, $A$ measures the range of intermediate goods that are available to the service sector. With constant returns to scale for a given $A$, the number of the firm cannot be determined from the profit maximization problem. We will assume therefore there are a large number of firms

The profit maximization problem for the service sector is to decide how much labor and how much of each intermediate goods should be utilized in production:

$$
\max _{L_{Y}, X_{j}} L_{Y}^{1-\alpha} \int_{0}^{A} X_{j}^{\alpha} d j-w L_{Y}-\int_{0}^{A} p_{j} X_{j} d j,
$$

Where $p_{j}$ is the price for intermediate goods, $j$ and $w$ is the wage paid for labor. The first-order conditions characterizing the solution are

$$
w=(1-\alpha) \frac{Y}{L_{Y}}
$$

and

$$
p_{j}=\alpha L_{Y}^{1-\alpha} X_{j}^{\alpha-1}
$$

where the first condition states that the firms employ labors until their marginal products is equal to the wage rate and the second condition is also the marginal condition applied for each intermediate good.

\subsection{The Intermediate Goods Sector}

The intermediate goods sector consists of monopolists who produce the intermediate capital goods which are sold to the service sector. These firms utilize their monopolistic power to purchase the design for specific intermediate goods from the research sector. Because of patent protection, only one firm manufactures each intermediate good.

According to Romer, we assume that once the design for particular intermediate good has been purchased, firms produces intermediate goods with a very simple production function that ensure the one to one translation of the row capital goods into final (intermediate) or capital goods. The profit maximizing problem for the intermediate goods sector is, therefore:

$$
\max _{X_{j}} \pi_{j}=p_{j}\left(X_{j}\right) X_{j}-r X_{j}
$$

where $p_{j}\left(X_{j}\right)$ is the service sector's demand function for intermediate goods. The first order condition for this problem is then,

$$
p_{j}^{\prime}\left(X_{j}\right) X_{j}+p_{j}\left(X_{j}\right)-r=0 .
$$

Rewriting this equation, we get a following elasticity expression:

$$
p_{j}=\frac{1}{1+\eta_{j}} r
$$

The elasticity $\eta_{j} \equiv p_{j}^{\prime}\left(X_{j}\right) X_{j} / p_{j}$ can be calculated from the demand equation of inter-mediate goods (5) and it is equal to $\alpha-1$. Therefore, the intermediate goods firm sets the price $p=\frac{1}{\alpha} r$ that is same for all intermediate goods and is a markup over marginal cost of knowledge. As the demand function of final goods sector is also the same, each intermediate good is inputted in the same amount: $X_{j}=X$. The total demand for capital from the intermediate goods sector must be equal to the total capital stock in the economy:

$$
\int_{0}^{A} X_{j} d j=K
$$

Since the capital goods are used in the same amount, $X$, is determined from this equation:

$$
X=\frac{K}{A} .
$$




\subsection{The Research Sector}

According to the Romer model we assume that the creation of new idea or knowledge depends on the stock of knowledge at that time and the number of researchers attempting to discover new ideas:

$$
\dot{A}=\delta L_{A}^{\lambda} A^{\phi}
$$

$A(t)$ is the stock of knowledge or the number of ideas at that time and $\dot{A}$ is the number of new idea produced at any given time. $L_{A}$ is the number of researchers and $\lambda, \phi$ are parameters between 0 and 1 .

In the case of creation of a new idea it depends not on the researcher himself only but on the research expenses or investment including labor cost of research. The production function of the R\&D sector, then, is:

$$
\dot{A}=\delta A s_{A} Y
$$

\subsection{The Aggregate Frame of the Model}

The final goods production function (2) can be rewritten, using the fact that $X_{j}=X$, as

$$
Y=A L_{Y}^{1-\alpha} X^{\alpha},
$$

and substituting from equation (10) makes the aggregate production function as:

$$
Y=K^{\alpha}\left(A L_{Y}\right)^{1-\alpha} .
$$

For a given level of technology, $A$, the production function exhibits constant returns to scale in $K$ and $L_{Y}$. However, as the technology level $A$ is also an input into production and it grows endogenously, it reveals an increasing return in the production of the economy as a whole.

The accumulation equations for capital and labor are identical to those of ordinary economic growth model.

$$
\dot{K}=s_{K} Y-d K,
$$

where $s_{K}$ is exogenously determined saving rate and $d$ is given rate of depreciation.

Labor is assumed to be equivalent to the population and to grow exponentially at some constant and exogenous rate $n$ :

$$
\dot{L}=n L \text {. }
$$

The production function of the R\&D sector, by assuming $\lambda$ and $\phi$ are equal to 1 on the equation (11), is:

$$
\dot{A}=\delta A L_{A} .
$$

And the alternative definition is finally, labor is used to produce new idea or to produce output in the service sector, so the resource constraint of the labor is as follows:

$$
L_{A}+L_{Y}=L \text {. }
$$

\subsection{Growth along the Balanced Growth Path}

Given a constant fraction of the population is employed in the R\&D sector along the balanced growth path, it is easily predictable that all per-capita growth is due to technological growth:

$$
g_{Y}=g_{k}=g_{A} .
$$

The per-capita output, the capital labor ratio and the stock of knowledge at the same rate along a balanced growth path. And this common growth rate can be attained by rewriting the production function of $R \& D$ sector, equation (16) as:

$$
g_{A} \equiv \frac{\dot{A}}{A}=n
$$

By applying the aggregate production function (16) and the production function of the $R \& D$ sector to the capital accumulation equation, the/a per-capita output on the balanced growth path can be shown as follows:

$$
y^{*}(t)=\left(\frac{s_{K}}{n+g_{A}+d}\right)^{\alpha / 1-\alpha}\left(1-s_{R}\right) \frac{\delta s_{R}}{g_{A}} L(t),
$$

Where, $S_{R}$ is share of researchers employed in the R\&D sector out of total labor force.

In this simple R\&D model, per-capita output is proportional to the population of the economy. In other words, the model exhibits scale effect in levels which arises basically from the non-rival nature of the technology. That is, in a larger economy can be provided on a larger market for technology and a raise on the return to research can be witnessed.

\section{Empirical Analysis}

\subsection{Estimation of the Growth Equation}

All the data utilized here are international cross country data from World Development Indicators 2012, published by World Bank. The descriptive statistics of the data is shown in the table 1 .

Table 1. Descriptive Statistics

\begin{tabular}{lllll}
\hline Variables & n & Mean & Std. Deviation & Minimum \\
\hline GDP Growth Rate & 82 & 3.934 & 2.298 & -0.400 \\
Share of Service Sector & 82 & 62.280 & 12.530 & 35.000 \\
Investment Rate & 82 & 5.235 & 4.627 & -3.200 \\
Population & 82 & 66.524 & 203.227 & 94.000 \\
\hline
\end{tabular}




\begin{tabular}{llllll}
\hline Variables & n & Mean & Std. Deviation & Minimum & Maximum \\
\hline Population Growth Rate & 82 & 0.768 & 0.998 & -1.000 & 3.000 \\
Share of Researcher & 82 & 0.00032 & 0.0072 & 0.000 & 0.00511 \\
Per-capita GDP & 82 & 18895.488 & 21697.007 & 320.000 & 98780.000 \\
\hline
\end{tabular}

Notes: The data are from World Bank, World Development Indicators 2012. Due to the data availability, 82 countries out of 216 countries opened all these 7 data. The name list of the countries is indicated in the table 2 below. The 'Share of Service Sector' is the share of service sector's value added out of total GDP and the 'Share of Researcher' is the share of the researchers employed in the R\&D sector out of total employed labor. 'Per-capita GDP' is indicated in 2012 U.S. dollar.

Theoretical Hypothesis expected from the growth equation (19) are as follows:

- Growth rate of GDP has negative coefficient because it is in the denominator of the equation (19).

- Service sector share has positive coefficient, and Investment rate has also positive coefficient because they are in the numerator of the equation.

- Population has positive coefficient and Jones (1997) call it the scale effects of knowledge creation.

- Population growth rate has negative coefficient.

- The Share of Researcher has positive coefficient.
The regression takes the form,

$$
y_{j}=\hat{\alpha}+\sum_{i} \hat{\beta}_{i} x_{i j}
$$

where, $y_{j}$ is dependent variable, $\hat{\alpha}$ is constant, $\hat{\beta}_{i}$ is estimated coefficients, and $x_{i j}$ stands for independent variables. Appling O.L.S. into the data set, we got an estimated results presented in the Table 2.

Table 2. Estimated Coefficients

\begin{tabular}{lllll}
\hline Variables & Coefficients & Std. Error & t-Statistics & significance \\
\hline GDP Growth Rate & -2464.1900 & 1222.6782 & -2.0154 & $*$ \\
Share of Service Sector & 843.4330 & 182.0279 & 4.6335 & $*$ \\
Investment Rate & -161.3577 & 612.3775 & -0.2635 & \\
Population & 11.3606 & 9.6794 & 1.1737 & \\
Population Growth & 2317.1840 & 2142.6667 & 1.0814 & $*$ \\
Share of Researchers & 6809966.2000 & 2603558.4000 & 2.6156 & $*$ \\
Constant & -27840.4000 & 12840.5100 & -2.1682 & \\
$\mathrm{R}$ & Adjusted R & $\mathrm{R}^{2}$ & Adjusted R ${ }^{2}$ & \\
0.6951 & 0.6647 & 0.4832 & 0.4419 & \\
\hline
\end{tabular}

Notes: Dependent variable is 'Per-capita GDP.' In the table, ${ }^{* *},\left(^{*}\right)$ means that estimated coefficient is significant in $1 \%(5 \%)$ level.

Service sector share has positive and significant coefficient which implies the positive growth effect of the service sector to the world economy. The share of researcher which implies the inputted labor force into $\mathrm{R} \& \mathrm{D}$ in this model has a significant positive coefficient as was expected. Because the new ideas and technology are embedded in the intermediate goods and capital goods and improve the productivity in the final goods service sector; innovation and technological progress in the service sector contribute to the world growth.

The coefficient applied to population is positive but it is not significant and, therefore, the scale effects of the R\&D has not been induced in the estimation. Population growth has positive coefficient which contradicts the theoretical expectations although it is not significant. In order to know development effects of R\&D in service sector investigation into underling causal structure of these variables will be needed.

\subsection{Causality Analysis}

Djellal et al (2003) indicated that R\&D projects in service sector improve the productivity and cause growth and development of the sector which generates growth and deepening in the economy. By hypothesizing their views, we will investigate the causality among the variables concerning R\&D and innovations in the service sector and world economic growth.

The statistical technique we utilize here is Principal component analysis (PCA). PCA is a statistical procedure that uses often to reveal the internal causal structure of the data in a way that best explains the variance in the data. If a dataset is a high-dimensional data, PCA can supply the user with a lower-dimensional picture of the underling causality structure. This is done by using only the first few principal components which have higher eigenvalue so that the dimensionality of the transformed data is reduced ${ }^{3}$.

Theoretical hypothesis

- R\&D in the service sector improves the productivity and causes the growth of the sector.

- Growth in the service sector will cause the economic growth.

- Growth in the service sector causes the deepening of the economy and increases the per capita GDP.

All the data utilized here are, again, from World Development Indicators 2012, published by World Bank. A descriptive statistics of the data is shown in the Table 3. Where 'Manufacturing,' 'Service Sector,' 'R\&D' mean the share of the sector's domestic products out of GDP.

\footnotetext{
${ }^{3}$ PCA is closely related to factor analysis. Factor analysis typically incorporates more domain specific assumptions than PCA about the underlying structure and solves eigenvectors of a slightly different matrix.
} 
'Government S.' means the percentages of the government spending out of GDE.

Table 3. Descriptive statistics

\begin{tabular}{llllll}
\hline Variables & n & Mean & Std. Dev. & Minimum & Maximum \\
\hline GDP Growth & 54 & 4.450 & 2.388 & 0.200 & 12.700 \\
Manufacturing & 54 & 14.296 & 6.663 & 1.000 & 34.000 \\
Service Sector & 54 & 59.556 & 13.842 & 33.000 & 94.000 \\
Investment Rate & 54 & 6.083 & 4.513 & -1.000 & 16.200 \\
Government S. & 54 & 4.767 & 4.333 & 0.000 & 21.200 \\
Per -cap. GDP & 54 & 15479.259 & 18093.572 & 230.000 & 59260.000 \\
Population & 54 & 83.389 & 247.668 & 1.000 & 1351.000 \\
Population G. & 54 & 0.852 & 1.188 & -1.000 & 3.000 \\
R\&D & 54 & 0.902 & 0.959 & 0.010 & 3.780 \\
Higher Education & 54 & 4.885 & 2.164 & 0.800 & 12.800 \\
\hline
\end{tabular}

Notes: 'Manufacturing', and 'Service Sector' are the share of their value added of total GDP. 'R\&D,' in this case, is the share of R\&D investment out of GDP. Due to the data availability, the number of the countries opened all these 10 variables in 2012 was 54.

Results of principal component analysis are shown in the Table 4 and Table 5. In the table 4, components with an eigenvalue larger than 1 are component 1,2, 3, 4 which we will depicted to the later analysis. The factor loadings of these components are indicated in the table 5 .

Table 4. Principal Component Analysis

\begin{tabular}{llll}
\hline Component & Eigenval. & Determin. & Cum. Det. \\
\hline 1 & 3.613 & $36.13 \%$ & $36.13 \%$ \\
2 & 1.622 & $16.22 \%$ & $52.34 \%$ \\
3 & 1.309 & $13.09 \%$ & $65.43 \%$ \\
4 & 1.104 & $11.04 \%$ & $76.47 \%$ \\
5 & 0.915 & $9.15 \%$ & $85.62 \%$ \\
6 & 0.465 & $4.65 \%$ & $90.27 \%$ \\
7 & 0.391 & $3.91 \%$ & $94.18 \%$ \\
8 & 0.318 & $3.18 \%$ & $97.36 \%$ \\
9 & 0.155 & $1.55 \%$ & $98.91 \%$ \\
10 & 0.109 & $1.09 \%$ & $100.00 \%$ \\
\hline
\end{tabular}

Notes: Eigenvalue is the variance of jth principal component. 'Determinant means the percentage of information conveys by the jth principal factor, and 'Cum. Det.' means cumulative determinant.

Table 5. Principal Components and Its Factor Loadings

\begin{tabular}{lllll}
\hline Variables/Com. & $\mathbf{1}$ & $\mathbf{2}$ & $\mathbf{3}$ & $\mathbf{4}$ \\
\hline GDP Growth & -0.7415 & 0.2426 & 0.3893 & 0.1473 \\
Manufacturing & 0.1709 & 0.8029 & -0.3952 & -0.1878 \\
Service Sector & 0.7576 & -0.1785 & 0.4235 & 0.0148 \\
Investment & -0.7156 & 0.2251 & 0.3105 & 0.2151 \\
Government Spend. & -0.6322 & -0.1147 & -0.1516 & 0.4886 \\
Per-capita GDP & 0.7471 & -0.1060 & 0.2605 & 0.5193 \\
Population & -0.2092 & 0.6948 & 0.3951 & 0.1634 \\
Population Growth & -0.5851 & -0.4944 & -0.1194 & 0.2288 \\
R\&D & 0.7649 & 0.2332 & 0.0936 & 0.3981 \\
Higher Education & 0.1359 & 0.1727 & -0.6748 & 0.5043 \\
\hline
\end{tabular}

Notes: Factor loadings means correlation coefficients between jth principal components and each variables.

For the component number 1, Per-capita GDP (0.7471), $R \& D$ ratio $(0.7649)$ and the service sector share $(0.7576)$ are the most influential elements. Manufacturing Sector Share (0.1709) and Higher Education (0.1359) have weak positive correlations with the component. Furthermore, GDP growth (-0.7419), Investment rate (-0.7156), Government Spending (-0.6322), Population Growth (-0.5851) and Population (0.2092 ) have negative relationship with the component. From these observations, we suppose the component number 1 as the developed economic stages or the deepening of economy related factor. Because R\&D ratio and the service sector share and per-capita GDP have higher correlation and manufacturing share and population growth have lower correlation with this component, a positive development effect of R\&D investment and growth in service sector share are implied in underling causality linkage.

For the Component number 2, Manufacturing Sector share (0.8029), Population (0.6948) and GDP Growth rate $(0.2426)$ have positive factor loading and then Investment rate $(0.2251)$ and $R \& D$ share $(0.2332)$ follow. Other variables have negative values of factor loading, such as Service sector share (-0.1785), Per-capita GDP (-0.1060) and Government spending $(-0.1147)$ which means these variables has negative relationships to the component number 2. From these observations, we can suppose the component number 2 as the economic growth related component. This component, therefore, implies higher growing economies' causality structure of these variables.

\section{Conclusion}

This paper had the aim to call up the importance of R\&D and Innovations on Tertiary Sector's Performance and Its Contribution to the World Economic Growth. In the first half of the section 3, we deduced positive growth effect of the service sector and R\&D activities to the world economy and which implies innovation and technological progress in the service sector contribute to the world growth. To investigate a causality structure more deeply, we applied principal component analysis on economic growth related data in 3.2. Two principal components relating to economic growth and development were deduced in the investigation. In the first principal component, a positive development effect of R\&D investment and growth in service sector share are implied in underling causality linkage. In the second principal component, on the other hand, we got higher growing economies' causality structure of economic growth related variables.

To improve the understanding and evaluation of $R \& D$ and Innovation in firms in which a certain number of service 
characteristics are becoming increasingly evident in products, behavior and modes of organization revisions such suggested earlier is needed. New definition of R\&D can bring some degree of consistency. And so the immaterial reference of service troubling their respective accounting seems to be more and more countered. Proof being given by the update done on the System of National Accounts Manual and on the Balance of Payments (2009) implementing new features regarding to services. According to data availability we could confirm the idea here supported. The category concerning the R\&D which production is no longer considerate as an intermediate consumption makes easier to evaluate the expending on. Instead of just take the value of assets obtained once frequently the expending about doesn't always give tradable assets (Vanoli 2008). And in this paper we would like to had data about researchers' population (in tertiary sector and others once it would be a service belonging to different sectors) so the factor loading analyze conclusions could have supplementary explaining empowerment.

We hope future working papers take in concern the results of the empirical part once continuous work is necessary to get deeper knowing on services real value on economy's evolving growth process.

\section{Acknowledge}

The authors gratefully acknowledge the attendants at the Tokyo Annual Business Conference 2014 on the Economics Session for their comments and suggestions contributing to the improvement of this paper: Prof. Mohammad Hoque, World Business Institute, Prof. Rutilio Martinez, University of Northern Colorado and Dianna DaCosta, Kobe University. This paper is dedicated to Professor Toshikazu Ito on the occasion of his retirement at Ryukoku University.

\section{Appendix 1}

List of the 82 countries appeared in the table 1.

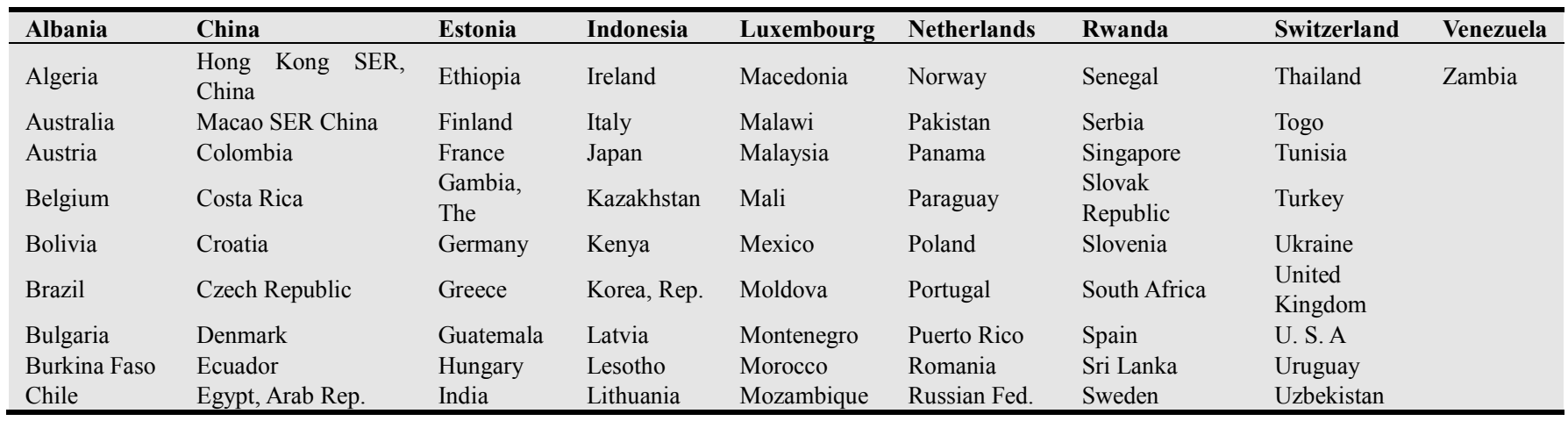

\section{Appendix 2}

List of the 54 countries appeared in the Table 3

\begin{tabular}{|c|c|c|c|c|c|c|}
\hline Australia & Colombia & Gambia, The & Japan & Netherlands & Singapore & Thailand \\
\hline Austria & Croatia & Germany & Kenya & Norway & Slovak Republic & Togo \\
\hline Belgium & Czech Republic & Guatemala & Latvia & Pakistan & Slovenia & Tunisia \\
\hline Bolivia & Ecuador & Hungary & Malaysia & Panama & South Africa & Ukraine \\
\hline Bulgaria & Estonia & India & Mali & Poland & Spain & United Kingdom \\
\hline Burkina Faso & Ethiopia & Indonesia & Mexico & Portugal & Sri Lanka & United States \\
\hline Chile & Finland & Ireland & Moldova & Senegal & Sweden & \\
\hline Hong Kong SAR, China & France & Italy & Morocco & Serbia & Switzerland & \\
\hline
\end{tabular}

\section{References}

[1] Barro, R. J. and X. Sala-i-Martine, 2004, Economic Growth (Second Edition), The MIT Press, Cambridge, Massachusetts.

[2] Djellal,F., Francoz D., Gallouj, C., Gallouj, F. and Yves Jacquin 2003, "Revising the definition of research and development in the light of the specificities of services" Science and Public Policy, volume 30, number 6, pages 415429, Beech Tree Publishing, 10 Watford Close, Guildford, Surrey GU1 2EP, England.
[3] Francisco J. B., and KABOSKI J. P., 2012, "The rise of the Service Economy", The American Economic Review, Volume 102, Number 6.

[4] Gordon, R.J., 1990, The Measurement of Durable Goods Prices, Chicago, Chicago University Press.

[5] Jones, C. I., 1997, Introduction to Economic Growth, W.W. Norton, New York.

[6] Manual, F. (OECD), 1993, Organization for Economic Cooperation and Development, Proposed Standard Practice for Surveys of Research and Experimental Development: Frascati Manual (OECD, Paris, fifth edition) 
[7] Romer, P. M., 1990, "Endogenous Technological Change," Journal of Political Economy, vol. 98, pp.s71-s102.

[8] Sahli, M. and Carey S., 2011, "Inbound Tourism and Economic Growth: A Review of Theory and Empirics," in Tisdal, C.A. ed., Handbook of Tourism Economics - Analysis, New Applications and Case Studies, World Scientific Publisher.

[9] Solow, R.M., 1957, "Technical Change and the Aggregate Production Function," Review of Economics and Statistics, vol.39, pp.312-320.
[10] Tanase, D. and Tanase, A., 2012, "The role of the tertiary sector in the growth of economic competitiveness", Annals Economics Science Series Central and Eastern European Online Library.

[11] Vanoli A., 2008, "La mise à jour du SCN 1993", Comments at the $12^{\text {th }}$ Association de Comptabilité Nationale Colloquium, Paris.

[12] World Bank, 2012, World Developmnet Indicators 2012, Yale University Press. 